\title{
Labor incentive and performance of the industrial firm: A case study of Bangladeshi RMG industry
}

\author{
Islam Md. Shafiqul, M.Com. ${ }^{1}$
}

\begin{abstract}
Bangladesh is a labor rich country and an ideal place for the Readymade Garment (RMG) industry that uses labor intensive technology for its production. Labor is an important factor for industrial production and it is truer in garment industry of Bangladesh. Human resource is taken to be an important factor to increase productivity and to improve quality as well as to reduce the costs of the production that is necessary to survive in the competition. There are several issues related to increases the labor productivities and among those, labor incentives is one of the major factor point. This study surveyed almost 36 medium and large scale RMG factories in Bangladesh with a focus on the improvement of productivity of RMG industries. This study finds that, the labor incentive programs increase firm performance and result in reduced delivery delay. Also, this study finds the level of education of the top level managements have an impact on the incentive programs of $R M G$ industries.
\end{abstract}

Keywords: Productivity, labor incentive, firm performance, $R M G$ industry and development.

\section{Introduction}

Bangladesh is on the way of her industrial revolution. It has just started her way from agricultural to industrial and at this moment the country is passing a crucial situation because of this turning. Agriculture is the backbone of this country but the manufacture and the service industries plays a very vital role in the country`s economy and day by day this dependency of those sectors are increasing. According to the World Bank (2011) report, total labor force in Bangladesh is 70,773,870 in 2009. ${ }^{2}$ The size of industry in GDP has increased from $15 \%$ in 2000 to nearly $30 \%$ in $2009 .{ }^{3}$ Bangladeshi industrial sector is dominated by readymade garment (RMG) ${ }^{4}$ sector and the economy as a whole depends heavily on RMG industry for at least last four decades. At present Bangladeshi RMG industry is competing with RMG sector giants, like India and China, using its relatively cheap labor. According to Bangladesh Bureau of Statistics (2009), approximately 3.1 million workers are employed in RMG sector, of which $85 \%$ of the labors are women. ${ }^{5}$ Since RMG sector is the biggest industrial sector in Bangladesh, the survival of this sector is very much important for the economic development of the country. Besides, the increasing competition in the international market has put this sector in vulnerable position recently. Bangladesh has opened up its economy in 1990s and since then economy is growing moderately with the increase in the export of RMG products. In this globalized and highly competitive world, Bangladesh needs to overcome its inefficiencies in production and other irregularities in the RMG industry to gain the highest profit from the low labor cost and also to keep international competitiveness in the RMG exports. For long run sustainability in international market, the industry must be concerned about the improvement in productivity. However, productivity is resulted from the efficiency of production, and productivity is the ratio of the total output to the total input. According to Bangladesh industrial development perspective, during early 2000, some medium and large scale RMG industries has taken some initial steps for its productivity improvement through technology adoption, investment in equipment, human resource and pay strategy, labor incentives etc. This paper discusses about the labor incentives programs and the firm performance in RMG industry of Bangladesh. The objective of the incentive programs are, i) To attracts the professional employee ii) To keep the performance better to employee iii) Motivates employee, to achieves superior performance ${ }^{6}$ for that particular company iv) To creates a competitive advantages among employees ${ }^{7}$ and, v) To keep the time track of delivery for the foreign customers (reducing lead time) ${ }^{8}$ of RMG production.

\footnotetext{
The author expresses his gratitude to hos supervisor, Dr. Sakai Kunio, Professor of Economics and Faculty of Commerce at Aichi Gakuin University, Japan, for giving his helpful advices, comments and suggestions, and mine correspondence address: 1-303 Dai-ichi-kanare, 1-107 Moritaka, Moriyama-ku, NagoyaCity-463-0035, Japan.

${ }^{2}$ Data source: World Bank, World Development Indicators - Last updated March 2, 2011

${ }^{3}$ Economic Survey of Bangladesh different years, 2005, World Bank, 2009 and Bangladesh Bank Statistics dat a, 2011

${ }^{4}$ Readymade Garment means ready for wear of dress which is made from fabric (Called as a RMG Product) by cutting, making and after trimming with manufacturing process. As a RMG product first of all cutting the fabric, and then making (with some accessories) and then trimming (Iron, packing) in factory. In Bangladesh, 1978 this type of RMG industry has been started as $100 \%$ export oriented industry.

${ }^{5}$ http://bgmea.com.bd/home/pages/aboutus Access in 2010.01.17

${ }^{6}$ Shun Linda Wang (2004), 'Incentives Compensation: Bonusing and Motivation', Chapter two, incentive systems, p.19. Massachusetts Institute of Technology,

${ }^{7}$ Ehrenberg and Smith, 2009, mention in chapter 9, Investments in Human Capital: Education and Training, p. 279-298.

${ }^{8} \mathrm{~A}$ lead time is the latency (delay) between the initiation and execution of a process. For example, the lead time between the placement of an order and delivery of a new car from a manufacturer may be anywhere from 2 weeks to 6 months. In industry, lead time reduction is an important part of lean manufacturing. Bangladeshi RMG industries are mostly taking order by letter of credit (L/C) for 90 days to 120days from manufacturing to delivery period.
} 
This paper focuses on the present scenario of labor incentive program in the RMG industry in Bangladesh. This paper is a study on 36 medium and large scales RMG industries to trace out the impact of the implication of the incentive packages on the work performance, profit and operational strategies of the industries. The rest of the paper is organized as follows. Section two, shows the history of RMG industry and evaluation of RMG industry in Bangladesh. Section three discusses, firm's performance and productivity improvement by informal (casual) labor incentive program for the RMG industries. Section four, covers the papers literature and hypothesis. Section five, data presentation and analyses the performance of labor incentives program to Bangladeshi RMG industries. Section six concludes the paper.

\section{RMG Industry Of Bangladesh: An Overview}

The industrial sector is dominated by RMG industry in Bangladesh, an export oriented industry, and it is well-known as goose that lays the golden eggs for over thirty years. This RMG industrial sector now-a-days dominates the modern economy in export earnings and employment generation. The RMG sector's contributions to the country's export earnings are around 77 percent. According to the Bangladesh Garment Manufacturer Exporters Association (BGMEA, 2010) ${ }^{9}$ and Bangladesh Bureau of Statistics (BBS), the employment opportunity for women labors in RMG sectors has raised by $85 \%$ from 2009 to 2010, creating more employment for women. The dependence on a single sector is a matter of policy concern, no matter how resilient or sturdy the sector is. Cheap and unskilled labors, and low energy cost, are among the reasons those are attracting both local and international investors into this sector. RMG factories in Bangladesh can be classified into Woven, Knitting, and Woolen industries.

Reaz Garments Limited ${ }^{10}$ has set the milestone by establishing the first RMG Industry in Bangladesh in 1978. Since then, more than 95 percent RMG firms are locally owned with an exception of a few foreign firms located in export processing zones (Gonzales, 2002). The RMG firms are mostly located in the capital city Dhaka, the port city Chittagong and the industrial city Narayangonj. Garments companies in Bangladesh form formal or informal groups. Different kinds of developments were seen in the RMG industry of Bangladesh for the last three decades. During the 1980s and 1990s, manufacturing process was mostly Cut, Make and Trim $(\mathrm{CMT})^{11}$. In the last decade, the traditional CMT production process changed into Composite Corporation $(\mathrm{CC})^{12}$ type of production process (cotton to fabric, fabric to design and printing, printing to dyeing and finishing, finishing fabric to RMG sample designing, cutting for the RMG product, Making, Trimming, Ironing and packing for export). Figure 1 shows some sample of Bangladesh RMG product which is continuously exporting.

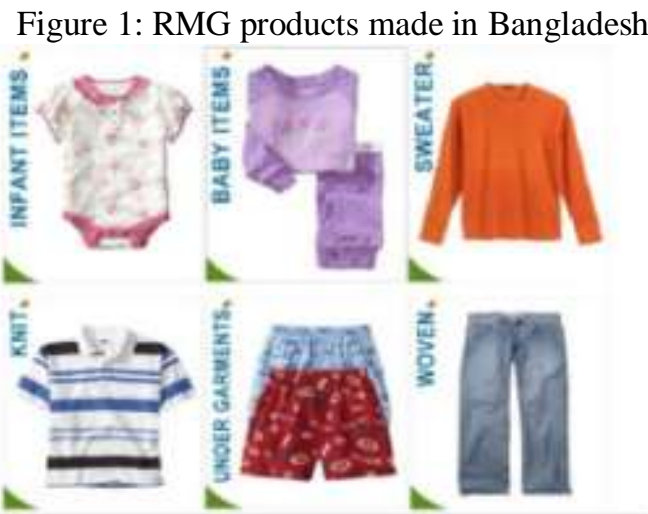

Source: Author, 2011

Bangladesh Export Processing Zone Authority (BEPZA) ${ }^{13}$ has been setup for the Foreign Direct Investment(FDI) investors for technological adaptation and improving the performance of the labor. But last

\footnotetext{
${ }^{9}$ The association is established in 1983 by 134 number of Bangladeshi RMG factories owners

${ }^{10}$ Its located in Urdu Road, Dhaka city as local order made tailoring shop namely Reaz Tailor, 1960 and 1978 it became Reaz Garments Limited as export oriented CMT based RMG factory. This garments factory was the first RMG product exporter in Bangladesh.

${ }^{11}$ CMT (Cut, Make and Trim): RMG product manufacturer involves in cutting, making, finishing and sourcing trims for any garment order. Buyer has to provide fabric and design to the manufacturer including all cost except freight cost. There is small, medium and large type of CMT factories in Bangladesh.

${ }^{12}$ Recently, a number of large firms with composite mills have emerged. These firms have both backward and forward linkage s. They procure orders from the retailers of US and EU (European Union) without the help of buying houses, produce fabrics, make the garments and export them. So, "CMT" scenario is changing. It also meaning group of companies where they can manufacture the RMG product begging to end using new type of production process \& technology. This type of manufacturing has started in Bangladesh at the beginning of $21^{\text {st }}$ century (Siddiqi, 2005).

${ }^{13}$ Export processing zone in Bangladesh which zone have special facilities and incentives to produce goods for export. First EPZ has built in 1980 and in 1993 at Chittagong and then Dhaka in 1996.Mainly for the Foreign Direct Investment (FDI) policy implications and it has attract the facility due to the 1994 to 2005 total workforce was 128,452 .
} 
three decade did not allow much due to pre-Multi Fiber Agreement (MFA) ${ }^{14}$ quota system which was implemented in Bangladeshi RMG industry. The investment in the RMG sector has been treated as one of the most profitable sectors with high return and government of Bangladesh has declared the textile sector as the Trust Sector in $1989^{15}$. The private investors have been investing in this sector and they mostly export to EU and USA markets. Gradually, RMG sector reflected the strength of Bangladeshi producers in the global apparel markets.

Therefore, at the first century of 2000, there are some medium and large scale of Bangladeshi RMG factories have started CC type of production process due to the end of MFA quota system in 2005. RMG sector is the only the sector in the economy that was able to create a large number of employment opportunities for the poor, unskilled, and especially for those who had migrated from rural areas. In addition, to continue its competitive position in the international market and also to increase the export growth, the RMG sector has changed its production style from CMT to CC.

\section{Contribution of the RMG Industry to Bangladesh Economy}

Compared to the other industrial sectors in Bangladesh, RMG sector has contributed the most in the GDP of Bangladesh and its economy during last two decades. The RMG export earnings have increased by more than eight times with an exceptional growth rate of $16.5 \%$ per annum. According to the Export Promotion Bureau and Bangladesh Bank (2011), the growth rate in RMG product export in 2005 to 2006 was $12.8 \%$ and in 2006 to 2007 is $23.1 \%$ which almost double growth rate, as shown in Table 1. The highest RMG products (woven and knit) export US\$12,346.3 million in 2009 where is about 15\% high growth then from 2008 and export US\$12,496.7 million in 2010.

Table 1: Category-wise Exports from 2005 to 2010(million US Dollar)

\begin{tabular}{|c|c|c|c|c|c|c|c|}
\hline No. & Items & FY05 & FY06 & FY07 & FY08 & FY09 & FY10 \\
\hline 1 & Raw Jute & 96.2 & 148.3 & 147.2 & 165.1 & 148.2 & 196.3 \\
\hline 2 & $\begin{array}{c}\text { Jute } \\
\text { Goods(excluding } \\
\text { carpet) }\end{array}$ & 307.5 & 361.0 & 320.8 & 318.3 & 324.9 & 534.5 \\
\hline 3 & Tea & 15.8 & 11.9 & 6.9 & 14.9 & 12.3 & 5.7 \\
\hline 4 & Leather & 220.9 & 257.3 & 266.1 & 284.4 & 178.2 & 226.1 \\
\hline 5 & $\begin{array}{c}\text { Frozen Shrimps } \\
\text { and Fish }\end{array}$ & 420.7 & 459.1 & 515.3 & 534.1 & 455.6 & 437.4 \\
\hline 6 & Woven Garments & 3598.2 & 4083.8 & 4657.6 & 5167.3 & 5919.0 & 6013.4 \\
$(41.58 \%)$ & $(38.8 \%)$ & $(38.25 \%)$ & $(36.62 \%)$ & $(38.03 \%)$ & $(37.11 \%)$ \\
\hline 7 & $\begin{array}{c}\text { Knitwear } \\
\text { Garments }\end{array}$ & $\begin{array}{c}2819.5 \\
(32.58 \%)\end{array}$ & $\begin{array}{c}3817.0 \\
(36.26 \%)\end{array}$ & $\begin{array}{c}4553.6 \\
(37.39 \%)\end{array}$ & $\begin{array}{c}5532.5 \\
(39.21 \%)\end{array}$ & $\begin{array}{c}6427.3 \\
(41.29 \%)\end{array}$ & 6483.3 \\
48 & Fertilizer & 130.3 & 124.1 & 125.1 & 91.3 & 107.5 & 38.6 \\
\hline 9 & Terry Towels & 64.8 & 80.2 & 106.0 & 112.9 & 117.7 & 157.1 \\
\hline 10 & Others & 980.6 & 1183.5 & 1479.3 & 1890.0 & 1874.5 & 2112.3 \\
\hline & Total Export & $\begin{array}{c}\mathbf{8 6 5 4 . 5} \\
(100 \%)\end{array}$ & $\begin{array}{c}\mathbf{1 0 5 2 6 . 2} \\
(100 \%)\end{array}$ & $\begin{array}{c}\mathbf{1 2 1 7 7 . 9} \\
(100 \%)\end{array}$ & $\begin{array}{c}\mathbf{1 4 1 1 0 . 8} \\
(100 \%)\end{array}$ & $\begin{array}{c}\mathbf{1 5 5 6 5 . 2} \\
(100 \%)\end{array}$ & $\begin{array}{c}\mathbf{1 6 2 0 4 . 7} \\
(100 \%)\end{array}$ \\
\hline
\end{tabular}

Source: Export Promotion Bureau, Collected by Bangladesh Bank, 2011.

Among the industrial sectors, the medium and large industries contributed to the Bangladeshi GDP most. Figure 2 shows the total export during 2009-10 by the in Bangladeshi medium and large industries. This export was about US\$643.8million where export of small industries is about US\$276.6 million.

\footnotetext{
${ }^{14}{ }^{14}$ Unilateral restriction, short-term arrangement (STA), long-term arrangement (LTA), Multifibre Arrangement (MFA) and finally the WTO Agreement on Textiles and Clothing (ATC) are the chronological steps through which the "export-quota system" was administered until it was finally abolished on 31 December 2004, making worldwide textile and garment trade quota-free. The system allowed importers to control the import of textile and garment products by imposing quantitative restrictions on exporting countries. For details on the system, see Agency for International Trade Information and Cooperation (1999); Hyvarinen (2000); Smith (1998); and Thongpakde and Pupphavesa (2000).

${ }^{15}$ In 1989, Bangladesh Government has been declared, privately invested in textile sector it is a trust sector and then in 1990 declared open economy for foreign investors through Board of Investment.
} 
Figure 2: Contribution of industries to GDP during 2009-10 (million in US\$)

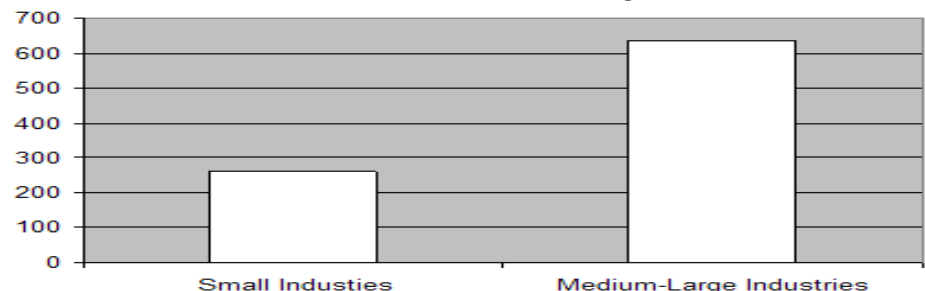

Source: Bangladesh Economic Review-2010 (Bangla version), Ministry of Finance

It is necessary to trace out the causes of large export volume by the medium and large scale industries as the share and contribution of medium and large scale industries plays a major role in the development of Bangladesh economy. Besides, it is necessary to study the labor development in medium and large RMG industries where mass production is possible by using cheap labor. The next section discusses the labor incentive and how it works in medium and large scale RMG industries. The next section also explains the dependence of the export performance of Bangladesh RMG industries on labor incentives programs.

\section{Firms Performance and Productivity Improvement by Labor Incentive}

Performance, in the context of industrial organization, is a broad concept which has been used to deal with productivity, efficiency, effectiveness, and more recently competitiveness (Cooke, 2000). As Cook has explained, labor productivity of a firm has long been the concern for labor economists ever since Marx and Smith. Using labor power effectively in production is subject to the management ability, and therefore, the managers can use various strategies to motivate labors to increase their efficiencies. One of such strategies is to provide varieties of incentives for labor. Following Cooke's ideas on performance through productivity, the Bangladeshi RMG industry too should use its own strategies to increase the labor productivity. The main aim of this paper is to discuss the RMG industrial development in Bangladesh through labor incentives.

Productivity is a measure of the efficiency of production. According to Saxena (2010), productivity is the ratio between inputs and outputs. Productivity is the concept which is used most often to evaluate the firm performance. Productivity is a measure of output from a production process, per unit of input. As a $6^{\text {th }}$ largest RMG exporter in the world, Bangladesh is now looking for the improvement of performance of its RMG industry further. Since Bangladesh is a labor rich country, its present concern is toward the improvement in labor productivity.

Increasing productivity bring many benefits to a industry and some those benefits increase profitability by lowering operational costs; optimizing the use of company resources; reducing environmental impact; increasing competitiveness and market share; and, providing opportunities for expansion ${ }^{16}$. As mentioned by Forfas (2009) and G. Blillikof (1992), productivity is influenced by many factors including labor incentives. Billikopf (1992) and Debapriya and Moazzem (2007) found that labor issues within industrial firms are critical for the firm performance at present. Figure 3 reveals other factors which are influencing on productivity improvement and firm performance. As same Figure 3 shows, for increasing firm performance some medium and large scale Bangladeshi RMG firms are investing to the labor facilities as casual incentives such as food, transport, housing etc.

Among the above mentioned factors, this paper focuses only on firms' performance through labor incentive program in Bangladeshi RMG industry. The poor and rural unskilled labors are working in Bangladeshi RMG industry. Since most of the garment workers are women, the following incentives should be provided to them. Factory owners, government agencies and even non-government agencies can come forward to help in this.

Labor productivity is the "average product of labor" (average output per worker, an output which could be measured in physical terms or in price terms). It is not the same as the marginal product of labor, which refers to the increase in output that result from a corresponding increase in labor input. The qualitative aspects of labor productivity such as creativity, innovation, teamwork, improved quality of work and the effects on other areas in a company are more difficult to measure.

${ }^{16}$ (Forfas 2009) 
Figure 3: Determinants factors of Firms' performance (The Conceptual Framework)

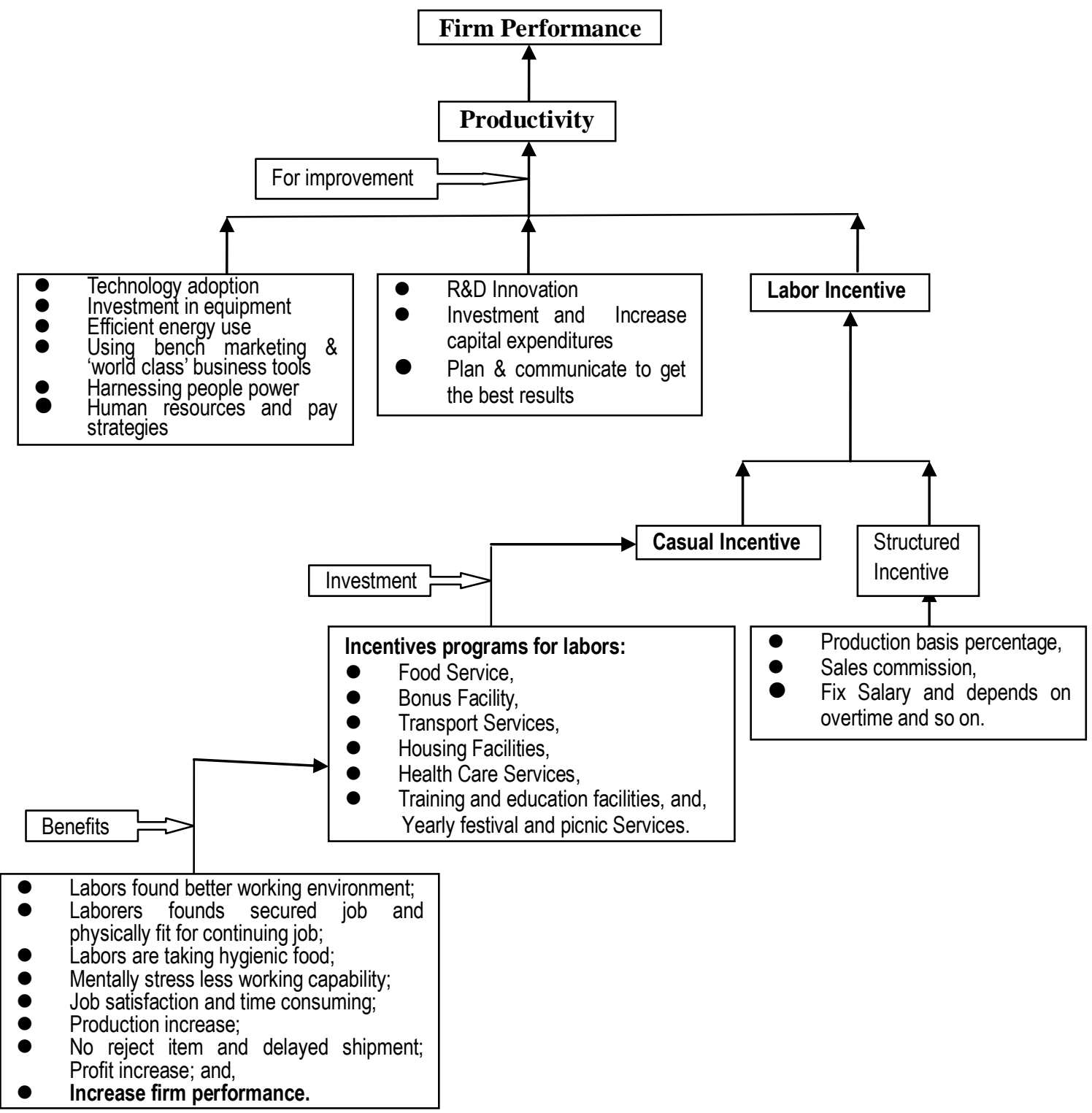

Source: Author, 2011

Labor Incentives: Labor is an important input in industrial production. Organizations use incentives to motivate their employees. This is common for the garment industry of Bangladesh. Human resource is considered to be an important factor in increasing the productivity, to improve quality and to reduce the costs of all necessary to survive in the competitive world. There are several issue related to labor. Industrial labor in the garment sector has undergone important changes over the two decades. Billikopf (1992) stated two types of incentive, i) Structured incentive, and, ii) Casual (informal) incentive. In this section the casual and structured incentives through the managers of the RMG factory in Bangladesh are discussed. Labor incentive is like the fuel for a car, without fuel it is not possible to drive a car, and likely the appropriate incentive programs will put the labors in high gear and motion to move forward toward the desired goal (Boesen, 2004). ${ }^{17}$

Structured incentives help employee's efforts directly. Other benefits include cost and cost reductions for the RMG factory owners. Benefits to employees include higher pay and job satisfaction. In structured incentives, workers are informed about the performance measures and the incentives. In a casual approach, workers never know when a reward will be given. Examples of structured incentives: A structured incentive (1) fluctuates (variable pay) as the performance level changes, and (2) is based on a specific accomplishment-reward connection well-known to both management and workers. Examples of typical incentives for making RMG product: piece-rate pay for picking, allowing laborers to go home early, with full

${ }^{17}$ UNDP, Conference paper \#8, incentives systems, incentives, motivation, and development performance, p.6, 2006 
pay, when they finish a job, end-of-season bonus for employees who stay to the end, quality or production incentive, bonus for reducing production costs, profit sharing.

Casual incentives mean informal incentives which are applicable to the companies/organization for the labors or employees, such as, food, transport, training, bonus and so on. Casual incentive is implied in private firms or organization and mostly in developing countries. As UNDP (2006) says, casual incentives are implicated only for the developing countries and not for the developed countries and it also mentioned public service incentives are weak in developing countries. The casual incentives attract many medium and large scales RMG factories in Bangladesh which will not be considered as a structured incentive. Casual rewards include such things as pat on the back, a sincere thank-you, a half price bill, a dinner, lunch and breakfast for free living cost etc. The objectives of the labor incentive program are to: attract the best labors, retain the high performing labors, motivate labors for superior performance and create a competitive advantage for the company (Wang (2004)). ${ }^{18}$ One of the many factors that directly affect a firm's profitability is employee productivity, so it makes sense to try to increase output whenever possible. Every labor and employee is an investment for a company. Having a happy worker means better production and loyalty to the company. Keeping the employees happy is a proven way to boost employee morale, which lead to better production, lesser day offs, and establish loyalty. Here some ideas which Bangladeshi medium and large scale RMG industries are adopting to motivate workforce to increase productivity and to perform at high levels.

i) Food Services: This is one of the best ways to increase employee motivation and improve their overall performance. Bangladesh is one of the most densely populated countries in the world and 1142 people are living per square kilometer area where population density is three times higher than India and nearly five times that of Pakistan (Shahidul, 2010). Due to population growth, food and agriculture products are becoming scares. In addition, rural people are migrating to urban to work and find it hard to purchase necessity items according to their salary. Moreover, preparing Bangladeshi traditional meals consume time and women are mostly responsible to prepare the meals as the male hardly enters the kitchen in Bangladesh. Therefore, the company owners can provide their workers with healthy and hygienic food. This will bring benefit to company in many ways. Firstly, it will result in a healthy work force, secondly, all workers can start and finish their work at same time, last but not the least, workers will be motivated to work with more positive attitude then before, fourth, job satisfaction will increase and therefore company don't need to recruit new and unskilled workers frequently, fifth, production performance of the firm will increase.

ii) Bonus Facility: Bonus is the increasing labors accountability, justifying objectivity of management, establishing clear expectations, aligning action to achieve goals or strategic objectives, and linking bonus rewards to performance (Wang (2004)). The goal setting, in the incentive based bonuses, gives labors the satisfaction of reaching goals, and seeing where future improvement may lie. By paying bonus to labors, it is easy to evaluate his/her performance in a collaborative manner, allowing for sharing of managerial views on labor contribution to the success of the firm and the profits of the firms are distributed to the labors. If the labors are dissatisfied with the bonus at the end of the year, it might be resulted in lowered productivity, limitations to the improvement in motivation and finally seeking employment elsewhere. If the labors do not see a direct correlation between performance and bonus, this may lead to a lack of motivation because employees see no reason to perform better (Wang, 2004). RMG industries in Bangladesh mostly depend on the unskilled and cheap labors. Paying bonus instead of improving the skill of the labors will induce the unskilled labors to stay with the company and thus the firm performance will not improve. Rather, improving the skill of the labors as well as providing bonuses will add profit to the company through increasing the efficiency of the labors.

(iii.) Transport Services: In Bangladesh, the transportation facilities are not friendly at all to women. It is mainly due to the fact that Bangladesh is a highly sex-segregated society and women mobility is restricted to some extent. Thus women only bus service can be started so that the women workers can travel to and from their workplace more easily. It would not be too hard as most of the workers of a factory tend to live together. Therefore, if the Bangladeshi RMG factory owners arrange the transport facility, then at same time all workers can start on their work. Besides, transport service is essential for all the labors as it is difficult to commute during the office hours. Bangladesh is a Islamic cultural society and women are not allowed to seat with men, thus, separate transport facility is necessary to carry the women labors only. Then women secure job satisfaction and production performance of the firm will be increase.

(iv.) Housing Facilities: In search for a better living standard, the young female workers are migrating from the village to work (mostly in RMG sector), and the low income level forces them to live in unhygienic and insecure places. As a result, they are often stressed during their work and it leads to decrease in productivity. RMG factory owners can provide them cheap, secure and hygienic housing facilities. And if the company setup housing facility for the workers then it will definitely encourage them to work without much stress. Sometimes company also needs overtime work to complete its production orders and shipment in time. If a company

${ }^{18}$ Sharpnack, Rick. Compensation in the Construction Industry, FMI: Management Consultant to the Construction Industry 
provides housing facility, it will help the company to get overtime work too. This will result in a decrease in the lead time, and an increase in productivity.

(v.) Health Care Services: Most of the health hazards among the garment workers arise due to the owners' non-compliance of labor laws. Lack of health care facilities is also greatly responsible for the ill-health of the workers employed in the garments industry. The absence of medical facilities and, lack of leave facilities should be blamed for the workers ill-health. Sometimes the employers do not let the workers out of the factory for a short time for medical purposes. Thus, there is an immediate need for providing medical assistance to the workers at the doorstep of the factory. Factory owners and non-government agencies should set up mini-clinics at factory premises for the workers to avail medical treatment regularly. Regular medical checkup at the cost of company cannot be treated as real cost to the company as the productivity will increase with healthier workforce. On the other hand, workers also enjoy this facility as they can save money and time from this medical facility.

(vi.) Training and Education facilities: Most of the garment workers enter the job market without any prior training or education. They mostly learn through on the job training. However, their productivity could be greatly increased if they were given skill training and other necessary education for an industrial worker ${ }^{19}$. Prior training will motivate the unskilled labors to join with the existing workforce without many conflicts. Training and education will also lead to increase productivity without spending much financial resources and time.

vi) Yearly festival and picnic Services: Internationally followers' holidays and cultural holiday's facilities are available for laborer in Bangladesh. In addition, yearly they have a tour/picnic party in certain places where they perform their activity in accordingly. Most of the privately owned companies are providing these facilities. Annual sports and cultural programs are arranged according to the companies' performance. These activities reduce the mental stress of the labors resulted by engaging in a routine work. This type of outbound trip and activities will build strong relationship among the workers. Further these will help to create job related team work and perform as a team in a factory or a firm. Although it is costly to keep employee satisfaction at a high level, every wise businessman knows how important this is. It certainly is a good investment; a happy employee makes a happy profit.

To avoid confusion to the readers, it should be noted here that the arguments of this paper is not relevant to the $\mathrm{R} \& \mathrm{D}$ innovation, human resources and other factors for the productivity improvement on industrial development process, rather this paper will discuss about the technological adoption, because it focuses mainly a firms performances increase through labor incentives programs.

\section{Technological adoption or innovation}

The latest technological innovations foster business by using the latest hardware and software to upgrade the machineries and equipments. For example, owners can install a program to record the operational activities and to measure productivity instead of using manual labor in record keeping, which is essentially unnecessary labor. It could not only increase output, but also hasten the jobs needed to be done. Adding productivity to the company or organization rests entirely on your ability to balance all the factors in business management. Yet the balance should not neglect any aspect in favor of another which can lead to undesirable consequences.

As discussed the literature on labor incentives, this paper will focus on whether this issue applicable to Bangladeshi RMG industries as well. For this purpose empirical data set collected from randomly selected 36 firms is used.

\section{Literature, Methodology and Hypothesis}

\section{Literature}

Several studies have found productivity effects from introducing pay for performance. Seiler (1984) finds that workers paid by piece rate earn higher pay due in part to higher effort, and in part to a risk premium. Lazear (2000) finds a 44\% productivity increase in a windshield installed company, and attributes about half of this to incentives and half to sorting. Paarsch and Shearer (1999 and 2000) found that productivity differential among tree planters paid by piece rates, relative to those paid by a fixed salary. Guiding the labors and making them motivate are critical dimensions for enhancing the firms' productive capacity. The capacity of concept is defined as "the ability of people, institutions and societies to perform functions, solve problems and set and achieve objectives" (UNDP, 2006). Therefore, as mentioned in the same UNDP report the incentives and incentive systems are fundamental to developing capacities and to translating developed capacities into better performance.

The focus of this paper is on the incentives programs and the incentive systems that influence motivation and behavior of people or larger system performance in RMG industry in Bangladesh. This is

${ }^{19}$ As mentioned in chapter 9, Investments in Human Capital: Education and Training, Page 279-298 (Ehrenberg and Smith, 2009). 
because; Bangladesh RMG industry has to compete with more advanced countries in RMG sector such as China and India. In addition to competing with these countries via cheap labor, RMG factory owners should look forward to increase the labor performance, and for this, incentive systems and motivations are critical as they enable individuals and organizations to perform their functions effectively, efficiently and sustainably. Incentive, which can be measured in various ways, viz-a-viz, salaries, secondary benefits, and intangible rewards etc. have traditionally been used to motivate employees to increase their work performance (UNDP, 2006). Incentive systems reside within organizations, their structure, rules, human resource management, opportunities, internal benefits, rewards and sanctions, etc (UNDP, 2006). First, incentive systems do have a significant influence on the performance of individuals and second, the organization overall. In particular, in many developing countries the most persistent structural motivators and incentives are located at the societal level, such as security, rule of law, investment climate, civil service pay or legislation.

In order to increase labor productivity at the enterprise level, the industry should keep appropriate training, improvement of compliance situation, diversification of product mix, provision of entertainment facility, performance incentives, and good behavior towards workers (Mustafizur, Debapriya and Moazzem, 2007). Productivity is a measured of your company's return on investment (Farfas (2009)). Basically, it is an indicator of how efficiently one convert inputs to outputs- in other words, a ratio of what one put in (labor, raw materials or other resources) to what he gets in the form of end products or value added. According to Saxena (2010), productivity is the ratio between inputs and outputs. Output is measured by the number of garments produced by a line of sewing machine operators in a specific time frame. Labor efficiency is the comparison of the time spent working productively to the total time spent at work. To become more support to belief according to S., Linda Wang $(2004)^{20}$ investing incentive result, attracts the best employs, retain the high performance of the employee, motivate employee superior performance, and create a competitive advantage for the companies.

McKenzie and Lee (1998) have found that one of the most important reasons of incentive programs within the organization is that organizations are a collection of workers whose interests are not always aligned with the interests of the people who employ them. Usually, the performance-based incentive programs motivate individuals to work harder to achieve a higher performance (Barki \& Hartwick, 1989). According to Billikopf's (1992) incentive pay, also known as pay for performance is generally given for specific performance results rather than simply for time worked. While incentives are not the answer to all personnel challenges, they can do much to increase worker performance. Billikopf (1992) also mentioned incentives work well-they have either help motivate high worker performance.

The World Bank (2002) has explained that Bangladesh is greatest muscle to its people but lagging behind economic growth of technical and technological modernization. Bangladesh is ethically consistent, and well known hard worker and resilience under strain (World Bank 2002, p.6). The World Bank also mentioned, Bangladesh has no more alternatives in order to gain development, with the exception of properly utilizing its population. Bangladesh has a big labor market and it is necessary urgently to take proper implication for its labor income growth as suggested by the World Bank (2002), United Nations Development Program (UNDP, 1999) and United Nations Educational, Scientific and Cultural Organizations (UNESCO) (2000).

\section{Methodology}

The research paper is conducted through a case study of Bangladeshi RMG industrial sectors. For logical analysis purpose empirical data has been collected from 36 medium and large scale Bangladeshi RMG factories. Also used in this papers various trade and labor policy reports of Bangladesh; journals, research reports, scholarly reports; Bangladesh Bank report; Bangladesh Bureau of Statistics(BBS); World Bank annual report; documents published by NGOs on labor issues; and BGMEA activity report, project reports and so on.

\section{Hypothesis}

The main objective of this paper has been trying to find using two Hypotheses.

$\mathbf{H}_{1}$ : Educated managers tend to give labor incentives in order to make better firm performance.

$\mathbf{H}_{2}$ : Incentive for the workers creates positive impact on firm performance.

\section{Data presentation and analysis}

The researcher had been collected empirical data by direct interview from 36 medium and large scale RMG factories during the April to June of $2011 .{ }^{21}$ Those factories are located in commercial areas in cities like Dhaka, Mirpur, Malibagh, Banani, Gulshan, Baddah, Uttara, Dakkhin khan, Savar and Chittagong in

\footnotetext{
${ }^{20}$ Shun Linda Wang (2004), 'Incentives Compensation: Bonusing and Motivation', Chapter 2, incentive systems, page.19 Massachusetts Institute of Technology,

${ }^{21}$ According to the Bangladesh Garments Manufacturer Exporters Association (BGMEA, 2007) report Bangladesh has 45 to 50 medium and large scale of RMG product manufacturing industries and there are few turning to large scale manufacturing industries (Also, Rahman. 2008, D. Bhattacharya, 2009 and The Daily Starr Business Report, 2005), the author indicate and selected the 36 RMG factories as medium and large scale industries which list has been collected from Bangladesh BGMEA directory, 2007-2008. Almost 80\% data has been collected from Bangladesh medium and large scale RMG manufacturing industries.
} 
Bangladesh. The main reason for these periodical data is to identify the export growth performances of the RMG factories in the international market resulted from the implementation of labor intensive program.

As shown in Table 1, the export growth of RMG product is growing in international market, the empirical data has been taken pre and post-incentive program implementation to the medium and large type of RMG factories. Data of medium and large type of RMG industries has been collected to find out the number of shipment order delayed or cancel and finally yearly profit growth rate. Two hypotheses have been formed to find out the effectiveness of the incentives program. The questionnaires as shown in Appendix (with a total of 26 questions into 4 sections.) are organized as follow. First two sections argue on the first hypothesis; whereas the second hypothesis is proved with third and fourth part of the questionnaires. The first two sections of the questionnaires focused on the necessity of the top manager's qualification and experience. Data on pre and post incentive program implementation has been summarized in Table 5 to explain the growth of RMG product. The first section of the survey in the Figure 4 shows, almost all the medium and large scale RMG factories were formed approximately 20 to 25 years ago and the ownership of the company still remain the same.

Figure No. 4: 36 Medium and Large Industries Years of RMG Manufacturing After Establishment

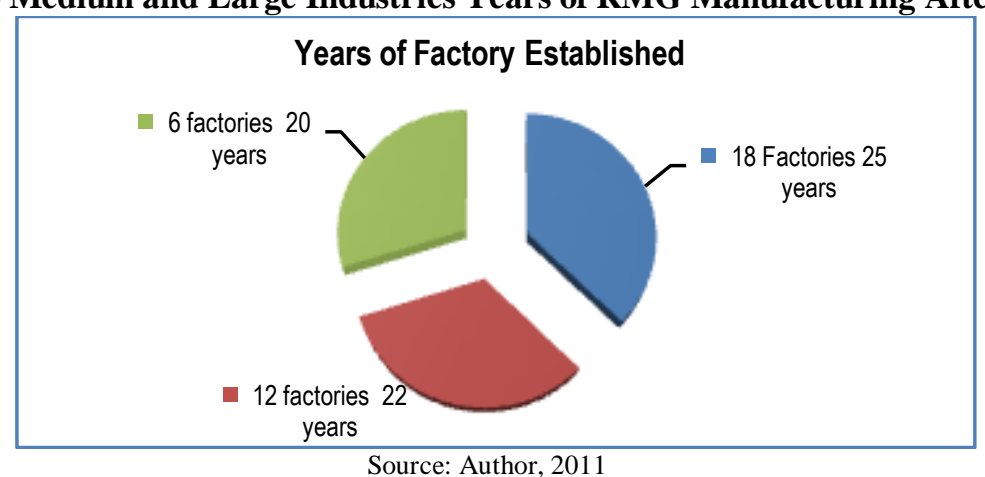

In Bangladesh, defense armed forces are the most disciplined among in service sector. So labor management is the one of the development factor to industrial development. As shown in Figure No. 5, $25 \%$ of the top managers or owners are armed forces or military field personally, whereas $30 \%$ of the top managers are from the RMG background. Therefore, the result also shows three categories top managers are accelerating the RMG industries export growth performance using their management skilled.

Figure No. 5: Top Managers Previous Occupation

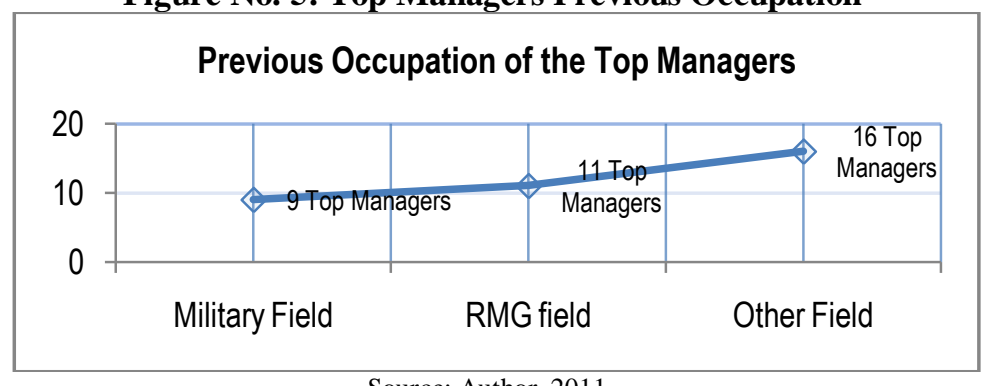

Source: Author, 2011

As shown in Table No. 2, characteristic and educational background almost $75 \%$ of the top managers have master degree in different subject, whereas $25 \%$ of the top managers have under graduate degree and $25 \%$ of the top managers have diploma in the RMG field related subject. In next section data shows, one of the important factors has been found of this result, all of top managers' job experience in RMG field more than 20 years. Moreover data result shows, $36 \%$ of the top managers have 4 years previous job experiences in different RMG factories and 53\% top managers have 2 years job experience same as another RMG industries as a employee. $47 \%$ of the companies surveyed is owned by one owner. However, it is easy to understand which is showing Table No. 2, most of the top managers are highly educated and they have been implicated the casual or informal labor incentive program to their own managerial firms. In addition, to find the reality from this study in Table No. 2 shows, education background of the 36 medium and large RMG industries top managers. 
Table No.2: Characteristics of Top Managers in Bangladeshi RMG industries

\begin{tabular}{|l|l|l|l|l|l|l|l|l|}
\hline & $\begin{array}{c}\text { Graduate } \\
\text { level }\end{array}$ & $\begin{array}{c}\text { Masters } \\
\text { level }\end{array}$ & $\begin{array}{c}\text { Extra } \\
\text { Diploma }\end{array}$ & $\begin{array}{c}\text { 20 years } \\
\text { \& more in } \\
\text { RMG field }\end{array}$ & $\begin{array}{c}\text { Extra 4 } \\
\text { years }\end{array}$ & $\begin{array}{c}\text { Extra 2 } \\
\text { years }\end{array}$ & $\begin{array}{c}\text { Self } \\
\text { 1(one) } \\
\text { owner }\end{array}$ & $\begin{array}{c}\text { Jointly } \\
\text { (More } \\
\text { then } \\
\text { 1owner) }\end{array}$ \\
\hline Managers Education Level & $25 \%(9)$ & $75 \%(27)$ & & & & & & \\
\hline Managers Job Experience & & & & $100 \%(36)$ & & & & \\
\hline $\begin{array}{l}\text { Managers Institutional } \\
\text { Diploma }\end{array}$ & & & $25 \%(9)$ & & & & & \\
\hline Professional Experience & & & & & $36 \%(13)$ & $53 \%(19)$ & & \\
\hline Factory established by & & & & & & & $\begin{array}{c}47 \%(17 \\
)\end{array}$ & $53 \%(19)$ \\
\hline
\end{tabular}

Source: Author, 2011.

The result and argues of this paper shows, "Educated top managers or owners tend to give labor incentives in order to make better firm performance."

The labor incentive program has been implicated by the educated top managers of Bangladeshi RMG industries and collected empirical data shows in Table No. 3, before and after investment of labor incentive program. The empirical data has been collected from medium and large scale RMG factories shows in two categories which are before incentive program (2001 to 2005), and after incentive program (2006 to 2010).

\section{Before the incentive program}

Due to many reasons, such as labor migration, unskilled, labor irregularity, political unrest strike, etc before incentive program there are large number of production order has been delayed in Bangladeshi medium and large scale of RMG industries. The data shows in Table No.4, 309 production orders complete in 2001 year by 36 medium and large scale RMG industries where total 97 of production order is delayed. Ultimately shipment has been complete number of total 309 and top managers found yearly profit of the factories only 5\%-10\% only. The last figure also says in same table in 2005 year number of complete and shipment total 324 and delayed production has been found total 79 of production order. There are only same rang percentage of profit has been found by the top managers of the RMG factories.

\section{After incentive program}

One of the major findings of this paper is the reduction in the delayed shipment of orders after the implementation of the incentive programs. The Table 3 shows after invested the incentive program in 2006 the number of production order was total 327 and delayed production order became only total 21 and factories are shipped same figure of total 327.

Table 3: Difference of two periods before and after incentives program in Bangladesh RMG industries

\begin{tabular}{|c|c|c|c|c|c|c|c|c|c|}
\hline \multicolumn{5}{|c|}{ Before Incentive program } & \multicolumn{5}{|c|}{ After the Incentive program } \\
\hline Year & $\begin{array}{c}\text { No. of } \\
\text { production order } \\
\text { complete in } \\
\text { yearly(Total) } \\
\end{array}$ & $\begin{array}{c}\text { No. of } \\
\text { production } \\
\text { order delayed } \\
\text { in yearly(Total) }\end{array}$ & $\begin{array}{c}\text { Total No. } \\
\text { of } \\
\text { shipment } \\
\text { in yearly }\end{array}$ & $\begin{array}{c}\text { Increase } \\
\text { d Profit } \\
(\%) \text { in } \\
\text { yearly }\end{array}$ & Year & $\begin{array}{c}\text { No. of } \\
\text { production } \\
\text { order complete } \\
\text { in yearly(Total) }\end{array}$ & $\begin{array}{c}\text { No. of } \\
\text { production } \\
\text { order delayed in } \\
\text { yearly(Total) }\end{array}$ & $\begin{array}{c}\text { Total No. } \\
\text { of } \\
\text { shipment } \\
\text { in yearly }\end{array}$ & $\begin{array}{c}\text { Increase } \\
\mathrm{d} \text { Profit } \\
(\%) \text { in } \\
\text { yearly } \\
\end{array}$ \\
\hline $\begin{array}{c}200 \\
1\end{array}$ & 309 & 97 & 309 & $5-10 \%$ & & & & & \\
\hline $\begin{array}{c}200 \\
2\end{array}$ & 302 & 92 & 302 & $5-10 \%$ & & & & & \\
\hline $\begin{array}{c}200 \\
3\end{array}$ & 312 & 65 & 312 & $5-10 \%$ & & & & & \\
\hline $\begin{array}{c}200 \\
4\end{array}$ & 314 & 77 & 314 & $5-10 \%$ & & & & & \\
\hline $\begin{array}{c}200 \\
5\end{array}$ & 324 & 79 & 324 & $5-10 \%$ & & & & & \\
\hline & & & & & 2006 & 327 & 21 & 327 & $10-15 \%$ \\
\hline & & & & & 2007 & 339 & 14 & 339 & $15-20 \%$ \\
\hline & & & & & 2008 & 387 & 0 & 387 & $20-25 \%$ \\
\hline & & & & & 2009 & 418 & 0 & 418 & $25-30 \%$ \\
\hline & & & & & 2010 & 464 & 0 & 464 & $25-30 \%$ \\
\hline
\end{tabular}


The implementation of the incentive programs resulted in $100 \%$ of the labors which has reduced the delayed shipment to zero in 2008. As in 2010, medium and large scale RMG factories profit has increased by $25 \%$ to $30 \%$ for the Bangladeshi RMG industries. Thus it is reasonable to say that the, "Incentive programs for the workers create positive impact on the firm performances".

\section{Conclusion}

Increasing the productivity of the labor remains at the core of increasing the competitiveness among the RMG industries. This increase in the productivity, in turn, depends on the level of technological advancements, wage incentives, working conditions and skill up-gradation programs. Bangladesh is yet to achieve all these elements to improve the labor productivity. Educated and experienced top managers of Bangladeshi RMG factories can help the business to earn more profit by investing in casual or informal incentive program for the labors. The structured incentive programs are not found in medium and large scale of Bangladeshi RMG industries as most of the privately owned RMG industrial sector in Bangladesh are more inclined to invest in the casual incentive program. It leads to the success of RMG industries as it increases the profit of the factories. After the implementation of the incentive program there is no complaining from the labors to the top managers about the food and healthcare facilities, attendance in the factory. The educated top managers mostly implemented the labor incentive programs in RMG industries and has been motivated the growth in export. Therefore, the performance of the firm depends on an institutional trained expert or an educated top manager.

Finally, as a manufacturing industry, RMG industries of Bangladesh are still highly contributing to its economy and popular as a profitable business. Most of the privately owned RMG industries are able to reduce their delay shipments to zero resulting in the foreign buyer's satisfaction by implementing incentives programs. Presently, this sector is trying to increase the quality of the product by using new technological production methods and also through skilled labors. In addition, training and assistance policies of Bangladesh government can bring success and growth to the RMG industrial sector through better performance by implementing the labor incentive program.

\section{References}

[1] Abdullah, Md. Abu Yousuf, 1997, "International Trade Implications and Future of Ready-Made Garments Sector of Bangladesh", Journal of Business Administration, Vol.23, No.3\&4, page41-69.

[2] Alec L., Cindy Z., Michael Gibbs and George Benson, 2011, Optimizing Incentive Plan Design: A Case Study, p.1 -24.

[3] Azim, M. Tahlil, and Nasir Uddin, 2003, "Challenges for Garments Sector in Bangladesh after 2004: Avenues for Survival and Growth", Bangladesh Institute of International and Strategic Studies Journal, Vol.24, No. 1, page 49-82.

[4] Bangladesh Export Promotion Bureau (EPB), Bangladesh knitwear Manufacturers Association, Information Division of EPB, 2008.

[5] Bangladesh Export Promotion Bureau, Bangladesh Export Statistics 2003-2004, Information Division of EPB, 2005.

[6] Bangladesh Garment Manufactures and Exports Association Garments \&Textile Directory (2007-08), Printers Division of EPB, 2009.

[7] Bhattacharya, D., M. Rahman, and A. Raihan, 2002, "Contribution of the RMG sector to the Bangladesh Economy", CPD Occasional Paper Series, Paper 50. Dhaka, Bangladesh.

[8] Bhattacharya, D., and M. Rahman, 1999, "Female Employment Under Export-propelled Industrialization: Prospects for Internalizing Global Opportunities in Bangladesh's Apparel Sector", UNRISD Occasional Paper. Dhaka, Bangladesh.

[9] Bhattacharya, D., and M. Rahman, 2000, "Experience with Implementation of WTO-ATC and Implication for Bangladesh", CPD Occasional Paper Series, Paper 7.Dhaka, Bangladesh.

[10] Billikopf, G. E. 1992, Establishing and Trouble Shooting Incentive Pay Programs (Chapter 83, pp.793-802). Large Dairy Herd Management, (Van Horn, H. H. \& Wilcox, Editors), Champaign, IL: American Dairy Science Association.

[11] Billikopf, G. E. 1996, Crew Workers Split between Hourly and Piece-Rate Pay (Vol.50-6) (pp.5-8). California Agriculture

[12] Bow, J. J, 2000, "Bangladesh's Export Apparel Industry into the $21^{\text {st }}$ Century - the Next Challenge", The Asia Foundation.

[13] CONFERENCE PAPER \#8 WORKING DRAFT, NOVEMBER 06, INCENTIVE SYSTEMS: INCENTIVES, MOTIVATION, AND DEVELOPMENT PERFORMANCE A UNDP CAPACITY DEVELOPMENT RESOURCE, Capacity Development Group, Bureau for Development Policy, United Nations Development Program, November 2006

[14] Centre for Policy Dialogue, 1999, "The Textile and Clothing Industry of Bangladesh: In a changing World Economy", CPD Dialogue Report No.18, Dhaka, Bangladesh.

[15] Centre for Policy Dialogue, 2003, "Coping with Post-MFA Challenges: Strategic Responses for Bangladesh RMG Sector", CPD Dialogue Report No.55, Dhaka, Bangladesh.

[16] Craig, C.; Harris, R. (1973). "Total Productivity Measurement at the Firm Level". Sloan Management Review (Spring 1973): 13-28.

[17] Dr Abdullah Al Faruque, 2009, Associate Professor and Chairman, Department of Law, University of Chittagong, Bangladesh. International Labor Organization 2009, University Press Published in 2009.

[18] Dr. Fang Lee Cooke, 2000, EWERC, Manchester School of Management, Manchester, UMIST, Human Resource Strategy to Improve Organizational Performance: a Route for British firms? Working paper No.9, ESRC Future of Work Program, ISSN 14691531, October 2000.

[19] Dr. Mohammad Mafizur Rahman, 2011, Senior Lecturer, Faculty of Business, University of Southern Queensland, Australia. 'Trade liberalization and gender gap: Bangladesh experience'

[20] GOB. 2010. Bangladesh Economic Review, Ministry of Finance, Government of Bangladesh.

[21] Islam, Sadequl, 2001, the Textile and Clothing Industry of Bangladesh in a Changing World Economy, CPD and the University Press Ltd.

[22] Jahan, Sarwat, 2005, "The End of Multi-Fiber Arrangement: Challenges and Opportunities for Bangladesh", WBI Policy Note.

[23] Katti, Vijaya and Subir Sen, 2000, “MFA Phasing Out and Indian Textile Industry: Selected Issues for Negotiation”, Foreign Trade Review, Vol.XXXIV, No.3\&4, Page 102-120. 
[24] M. Rahman, Bhattacharya, D., and K. G. Moazzem, 2007, "Bangladesh's Apparel Sector in Post-MFA PeriodExecutive Summary", Center for Policy Dialogue, Dhaka, Bangladesh.

[25] Mannur, H.G., 2000(second revised edition), International Economics, Vikas Publishing Pvt. Ltd., India.

[26] Md. Salim Uddin, Mohammed Abu Jahed, 2007, Garments Industry: A Prime Mover of the Socio Economic Development of Bangladesh, The Cost and Management, Vol. 35 No. 1, January-February, 2007 pp. 59-70, ISSN 1817-5090

[27] Mlachula, Montfort and Yongzheng Yang, 2004, "The End of Textile Quotas: A case Study of the Impact on Bangladesh", IMF Working Paper WP/04/08.

[28] Ronald G. Ehrenberg and Robert S. Smith, 2009, Modern Labor Economic: Theory and Public Policy, Pearson Edition, 2009.

[29] Shun Linda Wang, 2004, 'Incentives Compensation: Bonusing and Motivation', Chapter two, incentive systems, page no.19 Massachusetts Institute of Technology,

[30] Toshiaki, T., and Tetsuya, M., 2001, Aging Issues in the United States and Japan, Promotion, Incentives and Wages, p.335-360 University of Chicago Press.

[31] World Trade Organization, 2006, "Trade Policy Review”, Geneva.

[32] Y. Hossein Farzin and Ken-ichi-Akao, 2005, Non-pecuniary Work Incentive and labor supply, Giannini Foundation of Agricultural Economics.

[33] http://www.howtodothings.com/business/what-is-employee-satisfaction, access date 2011.03.30

[34] http://en.wikipedia.org/wiki/Lead_time , access date 2011.03.20 